\title{
Webjornalismo participativo como estratégia de legitimação
}

\author{
Eugenia Mariano Barichello e Luciana Menezes Carvalho
}

\section{Resumo}

Este artigo propõe uma reflexão sobre as práticas do webjornalismo participativo e a questão da auto-referencialidade enquanto estratégia de legitimação do campo jornalístico. Divide-se em três partes: a primeira aborda o fazer jornalístico, situando-o sob as lógicas da sociedade dos meios e da midiatização; a segunda aproxima as noções de webjornalismo participativo e auto-referencialidade para discutir a adoção destas práticas de exteriorização do fazer jornalístico. Finalmente, são colocadas algumas questões sobre o que esses fenômenos de abertura do campo podem representar em termos de legitimação/deslegitimação do próprio jornalismo enquanto instituição.

Webjornalismo participativo, Auto-referencialidade, Estratégias de comunicação, Midiatização, Legitimação

\section{Sobre as Autoras}

Eugenia Barichello é doutora em

Comunicação (UFRJ) e coordenadora do Mestrado em Comunicação da UFSM eugeniabarichello@gmail.com Luciana Menezes é jornalista (UFSM), com Especialização

em Comunicação Midiática (UFSM) e em Projetos Sociais e Culturais (UFRGS), Aluna Especial do Mestrado em Comunicação da UFSM lucianamenezescarvalho@ gmail.com

\section{Participative webjournalism as legitimation strategy}

\section{Abstract}

This paper proposes a reflection on the practices of participative web-journalism and the question of self-referentiality as a strategy to legitimate journalism as a field. It is divided in three parts: the first one approaches journalistic practice and analyses it under the logics of the media society and the mediatisation process; the second part approaches the notions of participative web journalism and selfreferentiality. It argues that the adoption of these practices of exteriorization of the journalistic practice. Finally, some questions are placed on what these phenomena of the opening of the journalism field can represent in terms of legitimacy/delegitimacy journalism as an institution.

Key words:

Participative web journalism, Self-referentiality, Communication strategies, Mediatisation, Legitimacy 


\section{Questões iniciais}

O objetivo deste artigo é refletir sobre as práticas do webjornalismo participativo e a questão da auto-referencialidade enquanto estratégia de legitimação do campo jornalístico. A hipótese aqui apresentada é de que a possibilidade de apuração, redação e postagem de informações pelo cidadão comum na web representaria, de certo modo, uma ameaça ao controle que o campo do jornalismo sempre teve sobre o que pode e o que não pode ser transformado em notícia, de acordo com seus critérios próprios de seleção ${ }^{1}$. Essa proposta não inclui iniciativas de cidadãos comuns que, sem o controle de jornalistas, publicam notícias na $w e b$, resumindo-se a uma reflexão teórica sobre o recurso da auto-referencialidade presente em seções participativas de sites jornalísticos. A principal questão levantada é que os espaços do tipo leitor-repórter e repórter-cidadão poderiam ser estratégias do próprio campo do jornalismo para se legitimar perante seu público.

O processo de midiatização - que através de um conjunto de operações sócio-técnico-simbólicas modifica as relações entre mídia, sociedade e atores sociais - expande-se de tal maneira que, assim como ocorre com os demais campos, o próprio campo midiático sofre seus efeitos. O jornalismo sofre estas implicações de maneira peculiar, conquistando cada vez mais autonomia. A autonomização dos campos sociais é uma das consequências da midiatização, e ela também afeta o espaço em que as notícias são produzidas. Campo social é aqui entendido como espaço legítimo perante a sociedade "para criar, impor, manter, sancionar e restabelecer uma hierarquia de valores, assim como um conjunto de regras" (Rodrigues, 1999:19). Nestes termos, o jornalismo tem se configurado, desde os primórdios da modernidade, como campo central na conquista de legitimação pelas demais instituições, inclusive promovendo a sua própria.

Entendemos que, com a midiatização, há um deslocamento nos critérios de legitimação do jornalismo, que antes eram fundados na idéia de "espelho" da realidade. Segundo Fausto Neto (2008:111) "a centralidade de lógicas das mídias empresta às práticas jornalísticas um novo regime de autonomia, não mais fundada numa 'vocação representacional' ". É quando o jornalismo se volta para seu próprio interior e passa a ficar mais transparente sua condição de discurso, de construção, que aumenta a necessidade de desmascaramento de seus mecanismos de produção das notícias, de exteriorização de seus bastidores. É a partir deste recorte que se constata a emergência do discurso auto-referencial em alguns produtos jornalísticos, prática que não é de hoje, mas que adquire novos contornos com o crescimento do jornalismo na internet.

Com a rede mundial de computadores, e o surgimento de novos modos de produção, circulação e recepção das mensagens, a exteriorização de práticas antes exclusivas do campo do jornalismo pode

${ }^{1}$ Segundo a teoria do gatekeeper, a definição do que vai ou não ser publicado na mídia está ligada a decisões coletivas, passando por critérios profissionais como noticiabilidade, espaço, qualidade, interesses comerciais (Fonseca e Lindemann, 2007:91). 
ser elevada à potência máxima. Sites pessoais, blogs, comunidades virtuais, e o advento do webjornalismo participativo ${ }^{2}$ são exemplos da liberação do pólo de emissão (ver em Lemos, 2003), que antes se concentrava nas empresas jornalísticas. A aproximação da noção de auto-referencialidade com a idéia de webjornalismo participativo não é aqui arbitrária, mas remete ao que já vem sendo proposto por Fausto Neto (2008), ao entender que estas práticas promovem uma exposição das operações que o próprio campo faz para representar a realidade, ou seja, deixam à mostra que as mensagens são construídas, exteriorizando os mecanismos por trás da produção das notícias.

O ciberespaço inaugura um novo horizonte, possibilitando, pela primeira vez na história, que o receptor atue também na condição de produtor de conteúdos ${ }^{3}$, exteriorizando os mecanismos de produção das mensagens aos quais, antes, só os especialistas deste campo de conhecimento tinham acesso. No entanto, soaria ingênuo resumir o jornalismo participativo na internet à realização de um ideal de cidadania, de um lado, ou a uma simples ameaça de destruição da profissão de jornalista, de outro.

A necessidade de legitimação das instituições torna-se questão central em um ambiente midiatizado, em que os campos sociais estão em constante luta por visibilidade. Segundo Barichello (2003:72), na atualidade "a obtenção de legitimidade passa por processos comunicacionais midiáticos, nos quais as instituições procuram explicar-se e justificar-se perante uma sociedade que recebe e reelabora essas informações". Entendendo-se o jornalismo como um campo que responde em grande parte pela legitimação das instituições no espaço público contemporâneo, a auto-referencialidade pode ser vista como estratégia de manutenção de poder.

A reflexão divide-se em três partes a partir daqui. Na primeira abordamos O Fazer Jornalístico - da Sociedade dos Meios ao Espaço Midiatizado, situando o campo do jornalismo em sua condição de produto de uma construção social em oposição ao ideal de campo neutro mediador. Posteriormente, em Webjornalismo Participativo e Auto-referencialidade, aproximamos as duas noções para discutir a adoção dessas práticas de exteriorização do fazer jornalístico. Finalmente, levantamos algumas discussões sobre o que esses fenômenos de abertura do campo podem estar representando em termos de legitimação/deslegitimação do próprio jornalismo enquanto instituição.

\section{- fazer jornalístico: da sociedade dos meios ao espaço midiatizado}

As teorias que conceberam a mídia como espelho da realidade campo neutro para o qual os demais campos convergiriam, e através do qual o real seria reproduzido - marcaram o processo de fundação institucional do jornalismo, vinculando ao seu fazer o discurso da objetividade. A partir da adoção do jornalismo norte-americano

${ }^{2}$ Também chamado de jornalismo cidadão, open source, colaborativo, comunitário etc. (Lindemann, 2006:154).

${ }^{3}$ Chamados de "co-gestores" por Fausto Neto (2008). 
como modelo hegemônico de imprensa, noções como imparcialidade e objetividade da linguagem passaram a ser associadas à credibilidade dos profissionais e veículos de imprensa, cunhando a idéia do que seria o bom jornalismo ${ }^{4}$. A linguagem objetiva, sem adjetivos, o distanciamento do jornalista no discurso, e o entendimento de que sua função é informar, relatar os fatos, atuando como intermediário entre os demais campos sociais e o público, marcam esta perspectiva - típica do entendimento de que a linguagem opera apenas uma intermediação. De acordo com esta proposta, os mecanismos envolvidos no processo de construção das notícias ficam ocultos do público, que tende a ver as mensagens como mera transposição. Com a crescente autonomia que os campos, e a própria mídia, experimentam na atualidade, vai havendo uma exteriorização das práticas antes ocultas de construção do real.

Ao abordar a questão da midiatização, Braga (2006) alude ao que poderia ser classificado como um processo de deslegitimação social, pelo qual os campos mediados pela mídia são dissecados em sua lógica interna. Neste contexto, a própria mídia se exterioriza, deixando visível seu funcionamento de bastidores. Sendo assim, a mídia não mais diz apenas o que é verdade e o que tem importância, mas passa também a mostrar as incertezas do mundo, deixando claro que as coisas não são dadas, mas construídas. Com relação ao jornalismo, esta abertura se dá pela auto-referencialidade, ou seja, "a ênfase da enunciação é voltada para a descrição das regras propriamente ditas que envolvem o trabalho da realidade da construção" (Fausto Neto, 2007:10). Em outras palavras, passamos da lógica de ocultação do processo de construção do campo jornalístico para uma outra em que sua condição de constructo fica evidenciada.

Nesse contexto em que os campos se exteriorizam, a idéia de que a experiência que temos da realidade é simplesmente mediada pelos meios de comunicação de massa torna-se insuficiente para dar conta dos fenômenos midiáticos contemporâneos. Autores como Sodré (2002), Braga (2006) e Ferreira (2007) propõem a noção de midiatização como uma alternativa teórica mais pertinente ao processo em curso. A inadequação da idéia de "mediação" deve-se ao fato de que mediar não é atributo exclusivo dos meios de comunicação de massa. A linguagem sempre opera uma mediação, como nos mostra toda uma tradição filosófica que reconhece o papel do sujeito na criação do real (ver Koff, 2003). A experiência do mundo é sempre através de um substituto para o real (no caso, o signo). Portanto, a mediação, nestes termos, não foi inventada pela mídia.

A pós-modernidade - com a fragmentação do conhecimento, a compressão espaço-temporal, a velocidade nos fluxos e a efemeridade ${ }^{5}$ - coloca a mídia no centro. Os meios de comunicação de massa deixam, assim, de ser vistos apenas como meios entre

${ }^{4}$ Em trabalho de conclusão do curso de Especialização em Comunicação Midiática, resgatamos a origem do princípio da objetividade no jornalismo brasileiro a partir da influência norte-americana (ver em Carvalho, 2006).

${ }^{5}$ Conforme pensada por Harvey (2001). 
o real e o sujeito, para se tornarem criadores de um "outro real", ou do único real possível e legítimo. De acordo com as teorias do "agendamento", só tem importância aquilo que é pautado pela mídia. Com a percepção de que os meios não podem ser neutros, muitas teorias foram para o outro extremo, denunciando o caráter de manipulação das mensagens da mídia - ela não mais mediaria, já que nesta perspectiva a sociedade apenas recebe de forma passiva os conteúdos, mas estaria sim criando uma outra verdade, distante de um real entendido como acessível. Superados os estudos de cunho ideológico, foi a vez dos estudos culturais e de recepção, com o foco nas mediações (ver em Polistchuk, 2003). O problema é que esta noção de mediação, dando ênfase na recepção e seus contextos, continua a não dar conta da complexidade dos processos sócio-comunicacionais, principalmente como ocorrem hoje.

Se o conceito de mediação já não se aplicava aos meios de comunicação de massa, imaginemos com as mudanças interacionais que emergem após o advento das redes digitais. Novas teorias tornaram-se cada vez mais urgentes, não simplesmente em função das novas tecnologias, mas das interações que delas derivam e nelas se operam, e da influência que exercem sobre os meios tradicionais. A mídia continua central, nossa experiência no mundo é inegavelmente mediada pelos meios de comunicação, mas a relação entre sujeito, sociedade e meios não é mais a mesma.

O protagonismo hoje, segundo a idéia de midiatização, não é desempenhado pelos media, mas pelas interações que deles decorrem ou com eles se estabelecem de forma complexa. As interações e construções sociais que giram em torno da mídia é que se tornam centrais na nova sociabilidade. Entra em jogo a idéia de processo em curso, um objeto que é dinâmico, o entre das relações proposto por Primo (2007). Dizer que a midiatização seja (ou esteja caminhando para se tornar) o processo interacional de referência (questão discutida por Braga, 2006) da atualidade significa entender que ela é o processo predominante, de maior relevância, funcionando como o principal direcionador na construção da realidade social. Pois, conforme Braga (2006, p. 19), “...o que faz a mídia é questão central e gera processos que dizem respeito a nossos modos de ser, passando a fazer, nuclearmente, parte da sociedade, quer sejam positivos ou negativos".

Para Ferreira (2007), a midiatização é definida a partir das relações e intersecções entre dispositivos midiáticos, processos sociais e comunicacionais. Pensar a midiatização nestes termos não implica em dotar de poder absoluto a mídia, tampouco encará-la como meio neutro. Para que se entenda a força deste processo na reconfiguração da sociabilidade contemporânea, tornam-
O protagonismo hoje, segundo a idéia de midiatização, não é desempenhado pelos media, mas pelas interações que deles decorrem ou com eles se estabelecem de forma complexa 
se pertinentes ainda as reflexões de Sodré, para quem a mídia nos dota de um "quarto bios", uma nova condição antropológica (uma espécie de avatar ou totem de nós mesmos no mundo virtual da existência midiatizada?). Seria "um novo tipo de relacionamento do indivíduo com referências concretas ou com o que se tem convencionado designar como verdade" (Sodré, 2002:27). A perspectiva que adotamos nesta reflexão resume-se na idéia de que "da mesma forma que o jornalismo constrói marcos interpretativos, ele é também resultado de um processo de construção" (Pereira:2007).

É a possibilidade de externar esta sua condição de discurso construído que o ambiente midiatizado atual traz, com a emergência de mensagens auto-referenciais nos produtos midiáticos e a oferta de espaços em que o leitor passa a ser, também, emissor. O uso sócio-técnico que se está fazendo destas novas possibilidades merece ser discutido. Estariam estes mecanismos de participação do leitor realmente promovendo uma abertura do campo jornalístico, socializando com o público seus mecanismos de construção da realidade e as implicações do processo de produção da notícia?

\section{Webjornalismo participativo e auto-referencialidade}

Levando-se em conta a exploração das características da tecnologia digital, o webjornalismo evolui a passos largos. Se, nos primórdios, os sites jornalísticos resumiam-se a meras reproduções das versões impressas dos jornais, que aos poucos foram incorporando hiperlinks e opções de interatividade com o leitor ${ }^{6}$, hoje há um número cada vez maior de produtos que convidam o público a atuar como produtor de conteúdo noticioso. A idéia de transformar internautas comuns em repórteres surge, no mundo, em iniciativas como Slashdot, Ohmy News, Wikinews (Lindemann, 2006:158). Com fórmulas e públicos diferentes, são exemplos nos quais as matérias são feitas parcial ou totalmente por usuários. Em alguns casos há uma checagem ou edição das notícias enviadas pelo público por parte de moderadores - jornalistas profissionais ou não, mas o princípio destes sites é ser uma alternativa aos meios de comunicação tradicionais.

O que nos interessa aqui são casos, como já afirmamos, de sites mantidos por empresas do meio jornalístico em que exista um espaço delimitado para a publicação de matérias elaboradas por pessoas comuns. Não pretendemos comentar as implicações relacionadas às seções colaborativas para publicação de fotos de internautas. Estamos nos referindo, por exemplo, ao que ocorre com a seção "vc repórter do Portal Terra", ou "Leitor-Repórter da zerohora.com", em que os leitores têm à disposição um espaço institucional, ou seja, oferecido e controlado por uma equipe e

${ }^{6}$ Mielniczuk (2003) divide o webjornalismo em três gerações, de acordo com a exploração das características do ciberespaço. Na primeira geração (ou transpositiva) os jornais na web são meras cópias das versões impressas; na segunda (metáfora) começam a ser incorporadas novidades como links para notícias de última hora e emails para que o leitor entre em contato com o jornal; finalmente no webjornalismo de terceira geração começam a surgir sites não atrelados a jornais ou empresas de comunicação já consolidadas, e há maior preocupação com a interatividade. 
que se insere em um produto maior de mercado, quer dizer, o site ou portal em que está localizado. É inevitável pensarmos na problemática da interatividade ou da cidadania ao abordarmos o webjornalismo participativo, mas por limitações de espaço em um artigo como este, e até mesmo em função de se tratar de uma reflexão mais exploratória, estamos nos atendo ao que propõe nosso título. Nosso foco está no uso estratégico dessas possibilidades pelo campo jornalístico que, midiatizado, busca trabalhar sua própria legitimação.

Por que entender essas práticas participativas na internet como uma forma de auto-referencialidade? Fausto Neto (2008) reconhece no jornalismo participativo na internet uma nova forma de explicitação dos modos de produção de sentido deste campo, com a dispensa da postura tradicional de opacidade enunciativa que marca o jornalismo moderno (calcado na objetividade). Com a transformação dos leitores em co-gestores da produção jornalística, o webjornalismo participativo seria, portanto, uma forma de o jornalismo chamar atenção para seu próprio discurso. De acordo com Soster (2007:01), "o sistema midiático acaba por sofrer um fechamento operacional em que os dispositivos passam a dialogar principalmente entre si, criando uma tecnoesfera social caracterizada pelo deslocamento da produção e oferta de sentido para seu próprio interior".

Segundo Braga (2006), a midiatização está relacionada a um processo de deslegitimação dos campos (ou sub-universos), com a exposição de suas entranhas, o que desmistifica uma série de conhecimentos e rituais que os delimitam e os mantêm. Ora, é o que ocorre com a midiatização do jornalismo. Neste caso, como se trata de campo dos media, a exposição de seus mecanismos internos de manutenção é sempre uma operação auto-referencial. Quando o campo abre para seu público o seu "como fazer", está operando nesta lógica. Mas, se quando se abre, uma área de conhecimento entra em processo de deslegitimação, o webjornalismo participativo estaria colocando em risco a legitimidade do campo jornalístico?

Deixar à mostra os mecanismos de construção da notícia, as implicações que lhe afetam, os critérios de seleção e as formas de apuração, ou seja, revelar que a objetividade jornalística é um discurso; a notícia sendo vista não como um relato do real, mas sendo dele apenas uma versão possível - tudo isto ocorre nas propostas existentes na internet hoje sob o rótulo de jornalismo participativo, jornalismo cidadão, colaborativo ou open source? Seja qual for sua denominação, seriam estes sites em que a notícia é feita por cidadãos comuns, representantes por excelência desta verdadeira abertura que a midiatização possibilita? E, assim sendo, seria também a incorporação da verdadeira ameaça
Seriam estes sites em que a notícia é feita por cidadãos comuns, representantes por excelência desta verdadeira abertura que a midiatização possibilita? 
que sofre o jornalismo enquanto campo discursivo e simbólico? A questão é que a abertura não é total, ela se dá dentro de um certo controle.

\begin{abstract}
Faz parte das relações esotéricas assumir alguns "conhecimentos" como acessíveis apenas aos "iniciados". Além disso, na manutenção do campo social, o processo de se expor a olhos "estranhos" se desenvolve nos termos e maneiras próprias do campo "esotérico" (pensar na medicina por exemplo). (Braga, 2006:24).
\end{abstract}

A auto-referencialidade já vinha aparecendo na programação midiática. Programas de tevê voltados para os bastidores da notícia são exemplos deste recurso, como é o caso do atual Profissão Repórter $^{7}$, assim como colunas de ombudsman publicadas em jornais impressos que já vinham externando alguns dos mecanismos internos de construção do jornalismo. Em geral, ao contrário de a abertura representar alguma ameaça à legitimidade do campo, acaba por ser mais uma estratégia de reforço de sua importância. Ao aproximar o leitor de seu universo de construção, convoca-o a uma espécie de renovação de contratos de leitura ${ }^{8}$. Pesquisas tendo como foco da investigação o recurso à auto-referencialidade no jornalismo têm mostrado consequências possíveis a esta dinâmica.

O já referido programa televisivo Profissão Repórter foi analisado em trabalho recente de Klein e Bastian (2008). Preocupadas com os "modos de endereçamento do programa que mostra os 'bastidores da notícia'”, as autoras apontam para o aspecto estratégico do meta-discurso midiático, que atua mais como um mecanismo de revalidação dos limites do campo jornalístico. Essa auto-referencialidade utilizada pelo programa não chega nem perto de ultrapassar os limites que garantem ao campo sua condição de especialidade. Ou seja, embora pareça dar ao espectador uma verdadeira devassa das técnicas de investigação utilizadas pelos repórteres na vida real, muitos aspectos que fazem parte do jogo jornalístico-midiático continuam intocáveis. "Não são enfocados negócios com patrocinadores, anunciantes, ou relações com políticos em estados em que os meios de comunicação estão sob o comando de uma personagem da política, por exemplo"( Klein e Bastian, 2008:12).

Fausto Neto (2008), ao se debruçar sobre a questão, tem trazido exemplos em que o dispositivo jornalístico se abre para falar de seu próprio discurso. Ao analisar a revista Imprensa, publicação dirigida principalmente a jornalistas e que tem como princípio editorial falar sobre o seu próprio campo, deixa claro que, também neste caso, a auto-referencialidade endossa ainda mais as especificidades do fazer jornalístico. Mesmo que transforme em

${ }^{7}$ Programa veiculado pela Rede Globo, apresentado pelo jornalista Caco Barcellos.

${ }^{8}$ Conceito recorrente nas reflexões de Fausto Neto, o contrato de leitura é entendido como "prática enunciativa', através da qual o jornal, enquanto sujeito, põe-se em contato com o leitorado", utilizando o termo também para outras mídias. 
acontecimento as rotinas internas ao campo, a revista, ao invés de provocar uma crise de legitimidade no campo do jornalismo, reforça sua condição de universo autônomo e especializado. O autor, em sua análise, aponta que a auto-referencialidade em Imprensa está em práticas como a transformação de jornalistas em verdadeiras celebridades.

Como se vê, o recurso à auto-referencialidade tem sido mais um apelo em busca de fidelização do público, que na internet assume ares de perigo real, podendo colocar em xeque valores fundadores do jornalismo enquanto instituição, como é o caso da credibilidade. Para Fonseca e Lindemann (2007:92), é o que ocorre quando o trabalho dos jornalistas resume-se ao gatwatching, ou seja, à simples edição do material bruto enviado pelo público, e "passa a ser de sua responsabilidade uma das atribuições que tradicionalmente as sociedades modernas atribuem aos jornalistas: a de produzir representações da realidade". No entanto, ao que tudo indica, essa representação do real parece continuar sendo uma atribuição que o campo do jornalismo toma para si, através do controle destes espaços de participação do público.

\section{Outras reflexões}

A passagem da lógica da comunicação de massas, em que imperava o modelo emissor-mensagem-receptor, para um processo de midiatização em que todos podem ser produtores de conteúdo, operou transformações substanciais no jornalismo. Através de práticas auto-referenciais, seus mecanismos internos de funcionamento são exteriorizados. Mas, na perspectiva aqui adotada, este recurso não é uma conseqüência involuntária da midiatização, ou seja, a visibilidade que o jornalismo dá para seu próprio fazer é uma estratégia, uma ação deliberada em busca de manutenção de legitimidade.

A exteriorização dos campos sociais, a partir da autonomia provocada pela midiatização, ao contrário de destruir sua legitimidade, muitas vezes a reforça. Isso porque as especificidades que mantêm um campo não chegam a ser devassadas a ponto de quem está de fora conseguir dominá-las, destituindo de poder os especialistas que nele atuam. A mídia, que é palco das estratégias de visibilidade das instituições, ao externar o funcionamento desses campos, também acaba por ameaçar o controle de seus atores. Mas, para se defender, estes adotam, no próprio cenário midiático, novas estratégias que lhe assegurem continuar com o poder sobre seus conhecimentos, técnicas e peculiaridades que mantêm o campo institucionalmente.

Com o jornalismo, em nosso entendimento, não é diferente. Até mesmo porque os empresários e profissionais da imprensa sabem bem como funciona esse processo paradoxal de abrir/fechar, desle-
A visibilidade que o jornalismo dá para seu próprio fazer é uma estratégia, uma ação deliberada em busca de manutenção de legitimidade 
gitimar/legitimar uma área de conhecimento ou um sub-universo social. Assim, ao se ver diante de uma nova ambiência, em que todos podem também atuar na produção de notícias, o campo do jornalismo utiliza-se da lógica própria desse novo espaço para se manter legitimado. As seções de webjornalismo participativo configuram-se, assim, em práticas auto-referenciais que têm como objetivo abrir o funcionamento do campo do jornalismo, dentro de um certo controle.

Ou seja, o campo, ao invés de se fechar, abre-se segundo certas regras. Se em alguns espaços mais livres (como blogs, sites colaborativos e comunidades virtuais) essa abertura pode representar uma ameaça real de deslegitimação, ao mesmo tempo em que socializaria sua condição de saber socialmente construído, nas seções dos sites e portais aos quais fizemos menção aqui é diferente.

Nas seções de webjornalismo participativo, o campo do jornalismo não é invadido por pseudo-jornalistas, mas os leitores são convidados a postar notícias elaboradas de maneira assumidamente amadora. Nestes casos, o jornalista profissional continua tendo uma função central, pois quando o internauta compara a notícia enviada pelo leitor com aquelas produzidas pela Redação, percebe a diferença, encontra lá os valores tradicionais que poderão atestar sua credibilidade. Desse modo, os espaços mais significativos destinados hoje, na web, ao jornalismo participativo, são estratégias de manutenção de poder por parte dos veículos de comunicação (e dos jornalistas) como detentores da boa informação em um espaço tão multifacetado como o da internet.

A participação dos leitores seria, assim, uma apropriação pelo jornalismo institucional de uma lógica que a sociotécnica impõe, tendo como objetivo (re)legitimar o campo do jornalismo como instância detentora da produção de notícias calcadas em critérios que atestam sua credibilidade. Contemplamos nesta reflexão apenas alguns aspectos, sem pretender encerrar o debate. As discussões aqui levantadas servirão de apoio para pesquisas, ainda em fase de projeto, nas quais pretendemos analisar seções de webjornalismo participativo em relação às estratégias autoreferenciais de legitimação do campo jornalístico na sociedade midiatizada.

\section{Referências}

ABREU, Alzira Alves de (Org). A imprensa em transição: o jornalismo brasileiro nos anos 50. Rio de Janeiro: Editora Fundação Getúlio Vargas, 1996, $199 \mathrm{p}$.

BARICHELLO, Eugenia Mariano da Rocha (Org). Visibilidade Midiática, Legitimação e Responsabilidade Social: dez estudos sobre as práticas de 
comunicação na universidade. Santa Maria: FACOS/UFSM, 2004, 366 p. Campo midiático, opinião pública e legitimação. In: SILVEIRA, Ada Cristina Machado et al. Comunicação e cultura midiática. Santa Maria: UFSM, 2003. p. 55-74.

BERGER, Peter L. LUCKMANN, Thomas. A construção social da realidade. Petrópolis: Vozes, 1994. $11^{\mathrm{a}}$ ed. 248 p.

BORDIEU, Pierre. Sobre a televisão. Rio de Janeiro: Jorge Zahar, 1997.

BRAGA, José Luis. Mediatização como processo interacional de referência. Santa Maria-RS. Animus. V. 5. n.2, p. 9-35, julho-dezembro, 2006.

CARVALHO, Luciana M. Desmascarando a Objetividade Jornalística: análise da cobertura de Veja no referendo do desarmamento. Monografia de Especialização. Santa Maria, UFSM, 2006. 15 p.

CHRISTOFOLETTI, Rogério. LAUX, Ana Paula. Confiabilidade, credibilidade e reputação: no jornalismo e na blogosfera. Intercom - Revista Brasileira de Ciências da Comunicação, v. 31, n. 1, 2008.

FAUSTO NETO, Antonio. Notas sobre as estratégias de celebração e consagração do jornalismo. Florianópolis-SC. Estudos em Jornalismo e Mídia. Ano V, n ${ }^{\circ}$ 01, p. 109-121, $1^{\circ}$ semestre de 2008.

Contratos de lectura: entre regulações e deslocamento. In: Diálogos Possíveis, (FSBA), v.6, 2007.

Mudanças da Medusa? A enunciação midiatizada e sua incompletude. ENCONTRO DA REDE PROSUL: Seminário sobre Midiatização, Sociedade e Sentido, 2007, Unisinos, São Leopoldo.

FERREIRA, Jairo. Midiatização: dispositivos, processos sociais e de comunicação. Brasília: e-Compós. n.10, dezembro de 2007.

FONSECA, Virginia. LINDEMAN, Cristiane. Webjornalismo Participativo: repensando algumas questões técnicas e teóricas. Revista FAMECOS. Porto Alegre, n. 34, dezembro 2007, p. 86-94.

HARVEY, David. A condição pós-moderna: uma pesquisa sobre as origens da mudança cultural. São Paulo: Edições Loyola, 2001.

HOHLFELDT, Antonio. BARBOSA, Marialva (orgs). Jornalismo no século XXI: a cidadania. Porto Alegre: Mercado Aberto, UFF e Intercom, 2002. 320 p.

KLEIN, Eloisa J. da Cunha. BASTIAN, Mariana. A quem fala o "Profissão Repórter"? Modos de endereçamento do programa que mostra os "bastidores da notícia”. ENCONTRO DA REDE PROSUL: Seminário sobre Midiatização, Sociedade e Sentido, 2007, Unisinos, São Leopoldo.

KOFF, Rogério Ferrer. Linguagem e Intencionalidade: a questão da objetividade e os limites da ética jornalística. In: 'A cultura do espetáculo: sete estudos sobre mídia, ética e ideologia' - Coleção Comunicação e Contemporaneidade. Santa Maria: FACOS-UFSM, 2003.

A informação jornalística na era do espetáculo. Revista Sociais e Humanas. Santa Maria: Centro de Ciências Sociais e Humanas, volume 18, número 1, janeiro/junho 2005.

LEMOS, André; CUNHA, Paulo (Orgs). Olhares sobre a Cibercultura. Porto Alegre: Sulina, 2003, p. 11-23. 
LINDEMANN, Cristiane. Jornalismo participativo na internet: novo suporte, novas práticas, novos conceitos. Revista Animus. Santa Maria, v. 05, n. 02, julho-dezembro, 2006, p. 149-168.

LINS DA SILVA, Carlos Eduardo. O adiantado da hora: a influência americana sobre o jornalismo brasileiro. $2^{\text {a }}$ ed. São Paulo: Summus Editorial, 1991.

LYOTARD, Jean-François. A condição pós-moderna. Rio de Janeiro: José Olympio, 2000. $6^{\mathrm{a}}$ ed, $131 \mathrm{p}$.

MARTINS, Francisco Menezes. Cyberespace e os sujeitos da interatividade. Brasília: e-Compós, agosto de 2007.

MIELNICZUK, Luciana. Jornalismo na Web: uma contribuição para o estudo do formato da notícia na escrita hipertextual. Tese de doutorado. Salvador, UFBA, 2003.

PEREIRA, Fábio Henrique. Jornalismo e construtivismo: a atividade como realidade socialmente construída. São Paulo. Revista Online PJ:Br - Jornalismo Brasileiro. Ano V, nº 09, dezembro de 2007. Disponível em F: $\backslash$ Artigo-material $\backslash$ Revista PJBr - Jornalismo Brasileiro.mht (acesso em 19/06/2008).

POLISTCHUK, Ilana. TRINTA, Aluízio Ramos. Teorias da comunicação: o pensamento e a prática da Comunicação Social. Rio de Janeiro: Elsevier, 2003. 179 p.

PRIMO, Alex. Interação mediada por computador. Comunicação, cibercultura, cognição. Porto Alegre: Editora Sulina, 2007. 240 p.

; TRÄSEL, Marcelo R. Webjornalismo participativo e a produção aberta de notícias. Rio de Janeiro, Revista Contracampo. V 14, p. 37-56, 2006.

RODRIGUES, Adriano Duarte. Experiência, modernidade e campo dos media. Lisboa: Universidade Nova de Lisboa, 1999. In: Biblioteca On-line de Ciências da Comunicação. Labcom.

Disponível em http://www.bocc.ubi.pt/_esp/autor.php?codautor=2 (acesso em 26/06/2008, 15h17min)

SODRÉ, Muniz. O ethos midiatizado. In: Antropológica do espelho. Por uma teoria da comunicação linear e em rede. Petrópolis: Vozes, 2002.

SOSTER, Demétrio de Azeredo. A midiatização do jornalismo. ENCONTRO DA REDE PROSUL: Seminário sobre Midiatização, Sociedade e Sentido, 2007, Unisinos, São Leopoldo.

TRIVINHO, Eugenio. Cibercultura e existência em tempo real. Contribuição para a crítica do modus operandi de reprodução cultural da civilização midiática avançada. Brasília: e-Compós, n.9, agosto de 2007.

Recebido em 08 de agosto de 2008 Aprovado em 08 de outubro de 2008 